\title{
Quantificação de açúcares totais e auxina no desenvolvimento inicial de mini- toletes de cana-de-açúcar
}

\author{
Bruno Teixeira de Sousa ${ }^{1}$, Valdir Zucareli ${ }^{2}$, Andréia Paula Carneiro Martins ${ }^{2}$ \\ ${ }^{1}$ Universidade Estadual de Londrina - UEL, PR. ${ }^{2}$ Universidade Estadual de Maringá - UEM, PR. E-mail: \\ bruno.t.sousa@hotmail.com
}

\section{Resumo}

Carboidratos de reserva e auxinas presentes no colmo estão envolvidos no desenvolvimento da planta de cana-de-açúcar. Objetivou-se quantificar o teor de açúcares totais e redutores e auxina do tipo ácido indolacético (AIA) no desenvolvimento inicial de colmos e gemas caulinares de cana-de-açúcar, em função do diâmetro e região do colmo. $O$ trabalho foi realizado em esquema fatorial $3 \times 3$ (diâmetro $x$ região do colmo), com quatro repetições. Foram utilizados colmos de plantas com 11 meses de idade, classificados em três diâmetros (fino $<2 \mathrm{~cm}$; médio $2-3 \mathrm{~cm}$; grosso $>3 \mathrm{~cm}$ ) e divididos em três regiões (ápice, meio e base). Os dados foram submetidos à análise de variância, e quando significativo as médias foram comparadas pelo teste Tukey $(p \leq 0,05)$. Nas variáveis bioquímicas (auxina e açúcares) houve maior interferência do fator diâmetro. Já nas variáveis biométricas (comprimento e massa seca de parte aérea e raízes, brotação e índice de velocidade de brotação), de maneira geral, a maior influência foi do fator região. $O$ diâmetro do caule interferiu no teor de auxina endógeno de colmos e gemas. $O$ crescimento de raiz mostrou-se relacionado à concentração de auxina endógena e a maior porcentagem de brotação foi obtida a partir da região apical, estando relacionada ao teor de açúcares redutores disponível. A utilização de mini-toletes para propagação da cana-de-açúcar mostrou-se viável.

Palavras-chave: dominância apical; hormônio vegetal; propagação; Saccharum spp.

\section{Total sugars and auxin quantification in the initial development of sugarcane mini-stalks}

\begin{abstract}
Reserve carbohydrate and auxins present in the stalk are involved in the development of sugarcane plant. Thus, this study aimed to quantify total sugars and auxin of type indoleacetic acid (IAA) content in the initial development of stalks and sugarcane buds, as a function of diameter and position in the stalk. The experiment was conducted in a $3 \times 3$ factorial scheme (diameter $x$ stalk section), with four replicates. Elevenmonth-old plants stalks were classified into three diameters (fine $<2 \mathrm{~cm}$; medium $2-3 \mathrm{~cm}$; thick $>3 \mathrm{~cm}$ ) and divided into three sections (apex, middle and base). Data were submitted to analysis of variance, and when significant the means were compared by the Tukey $(p \leq 0.05)$. The diameter factor resulted in greater interference in the content of the biochemical variables evaluated (sugars and auxin), in comparation to stalk section. Biometric variables (length and dry mass of shoot and roots, budding and budding speed index), in general, were mostly affected by stalk section factor. The diameter factor interfered in the content of endogenous auxin in the stalk and buds. Root growth was related to endogenous auxin concentration and the highest sprouting percentage was obtained from the apical section of the talk due to the availability of reducing sugars content. The use of mini-stalks for the propagation of sugarcane proved feasible.
\end{abstract}

Keyword: apical dominance; plant hormone; propagation; Saccharum spp. 


\section{Introdução}

De grande relevância no agronegócio brasileiro, a cana-de-açúcar na safra 2019/20 ocupou cerca de 8,4 milhões de hectares, com produção de 642,72 milhões de toneladas, colocando o Brasil no topo da lista de países produtores. A cana-de-açúcar é destaque na produção de biocombustível, devido ao seu elevado potencial na produção de etanol e geração de subprodutos de origem renovável (CONAB, 2019).

A cana-de-açúcar (Saccharum spp.) cultivada comercialmente é considerada um híbrido multiespecífico de espécies pertencentes ao gênero Saccharum L., que apresentam parte aérea composta por caule do tipo colmo, com folhas e panículas, e parte subterrânea composta por raízes e rizomas, e seu desenvolvimento se dá em forma de touceira (TOPPA et al., 2010; SOBRINHO et al., 2019). Os colmos apresentam nós e entrenós bem visíveis e distintos, e nas regiões do nó estão presentes os primórdios radiculares e as gemas, sendo a segunda, uma estrutura germinativa em estado de latência que em condições favoráveis emite um broto que dará origem a uma nova planta (THOMAS, 2016).

Nos entrenós estão presentes os açúcares solúveis de maior importância da cana-de-açúcar: a sacarose, em maior quantidade, junto da glicose e frutose em menores teores (BOARETTO, 2012). O diâmetro do entrenó do caule da canade-açúcar pode ser classificado como fino (medindo menos de $2 \mathrm{~cm}$ ), médio (apresentando de 2 à $3 \mathrm{~cm}$ ), ou grosso (medindo acima de $3 \mathrm{~cm}$ ), e tem correlação positiva com o acúmulo de reservas (SILVA; SILVA, 2012; MAIA JÚNIOR et al., 2018).

No cultivo destinado ao setor sucroalcooleiro a propagação dessa espécie é realizada de forma assexuada, através das brotações de suas gemas, de forma que os colmos são seccionados em toletes contendo de 3 a 4 nós, visando a superação da dominância apical exercida pela gema do ápice, e depositados nos sulcos de plantio (MAY; RAMOS, 2019). A dominância apical é descrita por Fagan et al. (2015) como resultado da produção de auxina no meristema apical, que mantém inibidas as gemas laterais das plantas. No entanto, essa dominância não é desejada nos propágulos que vão para o campo, onde é desejada a uniformidade das brotações (BARACAT NETO et al., 2017).

A brotação das gemas é um processo que consome energia, oriunda da degradação de substâncias de reservas do tolete como carboidratos, lipídeos e proteínas (MANHÃES et al., 2015; THOMAS, 2016). Após o plantio a disponibilidade de água é fundamental para o início do desenvolvimento do tolete, iniciando a ativação de enzimas e síntese dos hormônios promotores da divisão e alongamento celular; e a quantidade de reservas existentes nos toletes se torna fundamental para a sobrevivência da nova planta nos primeiros 60 dias, diminuindo conforme o desenvolvimento de parte aérea e raízes (LANDELL et al., 2012). No entanto, Namjoo et al. (2015) destacam que o número de gemas por toletes utilizados depende de fatores como variedade, método de plantio, condições ambientais e utilização de irrigação.

O método tradicional de propagação da cana-de-açúcar consome uma grande quantidade de colmos, em torno de 20 toneladas para plantar apenas um hectare (MAY; RAMOS, 2019). Em busca da inovação da prática propagativa da cana-de-açúcar, Civiero et al. (2016), destacaram a possibilidade da propagação da cana-de-açúcar utilizando mini-toletes contendo apenas uma gema, podendo resultar em redução de custos devido a menor exigência de material para propagação, menor mão-de-obra e utilização de maquinários mais eficientes. No entanto, essa diminuição de reservas pode afetar a brotação, crescimento e desenvolvimento inicial.

Levando-se em conta a fisiologia do desenvolvimento das plantas de cana-de-açúcar, espera-se que a brotação e desenvolvimento inicial das novas plantas com origem de minitoletes não seja dependente apenas da redução de reservas, mas também do tipo de reserva de açúcares e de hormônios vegetais disponíveis, que podem variar de acordo com a região e o diâmetro do colmo.

Nesse sentido, com o presente trabalho objetivou-se quantificar o teor de açúcares totais e redutores e auxina do tipo ácido indolácetico (AIA) em gemas e frações de colmos (minitoletes) de cana-de-açúcar em função da região caulinar e do diâmetro do colmo, assim como a interferência desses fatores no crescimento inicial das brotações.

\section{Material e Métodos \\ Coleta do material}

O experimento foi desenvolvido utilizando colmos de plantas de cana-de-açúcar com aproximadamente 11 meses de idade da variedade CTC 9001, colhidas de área de cultivo 
no campus da Universidade Estadual de Maringá, Campus de Umuarama (CAU). Essas plantas foram colhidas em primeiro corte, tendo origem da propagação assexuada convencional, e classificadas em três diâmetros segundo Silva e Silva (2012).

\section{Análises de composição química}

As análises para quantificação dos teores de açúcares totais (ATR), açúcares redutores (AR) e auxina do tipo ácido indolacético (AIA) foram desenvolvidas no laboratório da mesma instituição.

O delineamento experimental utilizado foi inteiramente casualizado e organizado em esquema fatorial $3 \times 3$ (diâmetro $\times$ região do colmo) totalizando nove tratamentos com quatro repetições. Cada repetição foi composta de duas plantas, de onde foram retirados cinco minitoletes com $3 \mathrm{~cm}$ de comprimento de cada região do colmo, totalizando 10 mini-toletes por parcela.

Os três componentes foram quantificados nas gemas e nas frações do colmo (mini-toletes). Para obtenção das amostras para quantificação dos componentes presentes nas gemas, elas foram retiradas do colmo utilizando-se uma faca, em seguida pesadas e maceradas em graal com $10 \mathrm{~mL}$ de água destilada. As amostras para análise dos componentes do colmo foram obtidas por meio de moagem, utilizando engenho manual. Foram coletados $10 \mathrm{~mL}$ do caldo para representar cada amostra. Durante a realização dos processos, as amostras obtidas foram acondicionadas em tubos de ensaio em uma caixa térmica com gelo e por fim levados à centrífuga a 3000 rpm por 10 minutos.

A determinação dos teores de AIA foi realizada por método Salkowski (GORDON; WEBER, 1951). Foram transferidos $1 \mathrm{~mL}$ de cada amostra diluída em água destilada (1:20) para tubos de ensaio de $10 \mathrm{~mL}$. Em seguida, foram adicionados $2 \mathrm{~mL}$ de reagente Salkowski $(1 \mathrm{~mL}$ de $\mathrm{FeCl}_{3}$ 0,5 M em $50 \mathrm{~mL}$ de ácido perclórico $35 \%$ ) em cada tubo, seguido de homogeneização. Após esse processo, os tubos foram deixados em repouso em ambiente tapado de luz e temperatura ambiente por 1 hora. Após esse processo, as amostras tiveram suas absorbâncias lidas em espectrofotômetro (UNICO SPECTROPHOTOMETER UV2100, UNITED PRODUCTS \& INSTRUMENTS INC), utilizando cubetas de vidro e comprimento de onda de 530 $\mathrm{nm}$.
Os teores de ATR foram determinados por método fenol sulfúrico (DUBOIS et al., 1956). Em tubos de ensaio de $10 \mathrm{~mL}$ foram transferidas alíquotas de $0,1 \mathrm{~mL}$ das amostras diluídas em água destilada (1:200), e adicionados em seguida $0,5 \mathrm{~mL}$ de solução de fenol (5\%) e $2,5 \mathrm{~mL}$ de $\mathrm{H}_{2} \mathrm{SO}_{4}$ concentrado. As soluções foram homogeneizadas e colocadas em repouso por 30 minutos. Após esses processos, as absorbâncias das amostras foram lidas em mesmo espectrofotômetro, em cubetas de vidro e comprimento de onda de $490 \mathrm{~nm}$.

E para teores de $A R$, foi seguido o método ADNS (ácido 3,5-dinitrossalicílico) (MILLER, 1959). Em tubos de ensaio de $10 \mathrm{~mL}$ foram adicionados $1 \mathrm{~mL}$ das amostras diluídas em água destilada (1:10) e $0,5 \mathrm{~mL}$ de solução de ADNS $1 \%$. Esses tubos foram colocados em banho maria a $100{ }^{\circ} \mathrm{C}$ por 5 minutos. Após esse processo, foram adicionados $5 \mathrm{~mL}$ de água destilada em cada tubo. As amostras tiveram suas absorbâncias lidas em mesmo espectrofotômetro, em cubetas de vidro, em comprimento de onda de $540 \mathrm{~nm}$.

As diluições foram necessárias para não estourar a leitura da absorbância. A estimativa dos teores presentes nas amostras analisadas foi obtida através de curvas de calibração, com diluições seriadas de solução de AIA $100 \mathrm{mg} \mathrm{L}^{-1}$ para AIA e solução de glicose $1 \%$ para ATR e AR. As concentrações são expressas em $\mathrm{mg} \mathrm{L}^{-1}$ para AIA e \% para ATR e AR.

\section{Análises biométricas}

Para as análises de brotação e desenvolvimento inicial de plantas, foi utilizado o mesmo delineamento experimental e esquema fatorial das análises de composição química. Essa fase do experimento foi realizada nos laboratórios de fisiologia vegetal e de análises de sementes da mesma instituição. O mesmo método foi utilizado para a obtenção dos minitoletes, porém, para essas análises as gemas não foram retiradas. Os mini-toletes foram selecionados quanto à aparência, estádio de maturação e ausência de danos físicos. Em seguida foram dispostos em bandejas de poliestireno expandido com capacidade de 500 $\mathrm{mL}$ contendo substrato (vermiculita) umedecido e cobertos com uma camada de $2 \mathrm{~cm}$ do mesmo substrato. As bandejas foram envoltas com filme de policloreto de vinila (PVC) e levadas para câmara de germinação à temperatura constante de $28^{\circ} \mathrm{C}$ e umidade relativa de $80 \%$ por 16 dias. 
A contagem do numero de gemas brotadas foi realizada aos quatro, seis e oito dias após a montagem do experimento para a obtenção dos dados para cálculo do índice de velocidade de brotação, e aos 16 dias na avaliação final para quantificar a porcentagem de brotos viáveis. A velocidade de emergência das brotações foi calculada através da fórmula proposta por Maguire (1962):

V.E. $=N_{1} / D_{1}+N_{2} / D_{2}+\ldots+N_{n} / D_{n}$

onde V.E.: Velocidade de emergência, $N_{n}$ : número de brotos emergidos nas contagens, $D_{n}$ : número de dias desde o plantio até a contagem.

O comprimento de parte aérea e raiz foram medidos aos 16 dias, utilizando régua milimetrada e em seguida cortadas dos minitoletes e colocadas em sacos de papel, que foram levados a estufa de circulação de ar à $65^{\circ} \mathrm{C}$ por cinco dias. Após esse período, o conteúdo de cada saco foi pesado em balança analítica eletrônica para obtenção dos dados de massa seca.

\section{Análise estatítica}

Os dados obtidos foram submetidos a análise de variância (ANOVA) por teste $F(p \leq 0,05)$, e quando significativo, as médias foram comparadas pelo teste de Tukey $(p \leq 0,05)$ utilizando o software SISVAR (Versão 5.6, DEX/UFLA).

\section{Resultados e Discussão}

Os colmos de diâmetro fino foram os únicos a apresentarem influência da região caulinar nos teores de AIA (Tabela 1). A quantidade dessa auxina na região apical dos colmos não foi influenciada pelo diâmetro, havendo diferença apenas nas regiões mediana e basal, onde colmos com diâmetro médio e grosso apresentaram as menores médias.

Tabela 1. Interação entre diâmetro e região caulinar nos teores de ácido indolacético (AIA) e açúcares totais (ATR) em colmos de cana-de-açúcar. $(n=4)$.

\begin{tabular}{|c|c|c|c|c|c|c|}
\hline \multirow{2}{*}{$D \times R$} & \multicolumn{3}{|c|}{ AIA $\left(\mathrm{mg} \mathrm{L}^{-1}\right)$} & \multicolumn{3}{|c|}{ ATR (\%) } \\
\hline & Ápice & Meio & Base & Ápice & Meio & Base \\
\hline Fino & $43,45 \mathrm{aC}$ & $83,91 \mathrm{aA}$ & $65,29 \mathrm{aB}$ & $21,32 \mathrm{aB}$ & 25,89 aA & $26,52 \mathrm{aA}$ \\
\hline Médio & $44,22 \mathrm{aA}$ & $35,03 \mathrm{bA}$ & $41,57 \mathrm{bA}$ & $6,54 \mathrm{bC}$ & $17,50 \mathrm{bA}$ & $12,84 \mathrm{cB}$ \\
\hline Grosso & 41,57 aA & $39,57 \mathrm{bA}$ & 38,46 bA & $9,55 \mathrm{bB}$ & $15,31 \mathrm{bA}$ & $17,91 \mathrm{bA}$ \\
\hline CV (\%) & \multicolumn{3}{|c|}{12,9} & \multicolumn{3}{|c|}{14,6} \\
\hline$F$ & \multicolumn{3}{|c|}{$18,82 * *$} & \multicolumn{3}{|c|}{$3,03 *$} \\
\hline
\end{tabular}

${ }^{* *}$ significativo a $p \leq 0,01$ de probabilidade. ${ }^{*}$ significativo a $p \leq 0,05$ de probabilidade. Médias seguidas de letras diferentes (minúsculas na coluna e maiúsculas na linha) diferem entre si pelo teste Tukey $p \leq 0,05$.

As regiões caulinares interferiram no teor de açúcares totais (ATR) em todos os diâmetros de colmo e, de maneira geral, maiores médias foram observadas nas regiões do meio e na base dos colmos (Tabela 1). Estes teores também foram influenciados pelo diâmetro, sendo as maiores médias encontradas em colmos de diâmetro fino.

O teor de açúcar redutor é menor em colmos de diâmetro fino e aumenta conforme o aumento do diâmetro (Tabela 2). As gemas com origem em colmos de diâmetro grosso proporcionaram as menores médias para os teores de AIA, ATR e AR, diferindo dos resultados das médias de diâmetro fino e médio. 
Tabela 2. Resultados das variáveis teor de açúcares redutores no colmo (AR C) e gemas (AR G), teor de auxina nas gemas (AIA G) e teor de açúcares totais em gemas (ATR G) para o fator diâmetro de colmos de cana-de-açúcar. $(n=4)$

\begin{tabular}{ccccc}
\hline Diâmetro & AR C (\%) & AR G (\%) & AIA G $\left(\mathrm{mg} \mathrm{L}^{-1}\right)$ & ATR G (\%) \\
\hline Fino & $0,86 \mathrm{~b}$ & $0,25 \mathrm{a}$ & $51,21 \mathrm{a}$ & $1,02 \mathrm{a}$ \\
Médio & $1,19 \mathrm{a}$ & $0,22 \mathrm{a}$ & $48,11 \mathrm{a}$ & $0,83 \mathrm{a}$ \\
Grosso & $1,28 \mathrm{a}$ & $0,12 \mathrm{~b}$ & $30,70 \mathrm{~b}$ & $0,41 \mathrm{~b}$ \\
\hline CV (\%) & 14,8 & 16,9 & 17,5 & 35,3 \\
\hline F & $21,26^{* *}$ & $47,44^{* *}$ & $25,39 * *$ & $16,08^{* *}$ \\
\hline
\end{tabular}

**significativo a $p<0,01$ de probabilidade. ${ }^{*}$ significativo a $p \leq 0,05$ de probabilidade. Médias seguidas de letras diferentes na coluna diferem entre si pelo teste Tukey $p \leq 0,05$.

O teor de açúcares redutores em gemas e colmos provenientes de diferentes regiões do caule de cana-de-açúcar está apresentado na tabela 3. Os valores para esta variável nos colmos foram diferentes para as três regiões, onde a região apical proporcionou a maior média, e a região basal a menor. Quando analisados os valores encontrados nas gemas, as localizadas na região apical proporcionaram a maior média, diferindo das demais regiões.

Tabela 3. Resultados dos teores de açúcares redutores em colmos (AR C) e gemas (AR G) de cana-de-açúcar em função da região caulinar. $(n=4)$.

\begin{tabular}{|c|c|c|}
\hline Região & AR C (\%) & AR G (\%) \\
\hline Ápice & $1,41 \mathrm{a}$ & $0,22 \mathrm{a}$ \\
\hline Meio & $1,07 \mathrm{~b}$ & $0,19 \mathrm{~b}$ \\
\hline Base & $0,86 \mathrm{c}$ & $0,18 b$ \\
\hline CV (\%) & 14,8 & 16,9 \\
\hline $\mathrm{F}$ & $34,41 * *$ & $6,02 * *$ \\
\hline $\begin{array}{l}\text { *significativo } \\
\text { significativo a } \\
\text { eguidas de letra } \\
\text { i pelo teste Tuke }\end{array}$ & $\begin{array}{l}\text { a } \quad p<0,01 \\
p \leq 0,05 \text { de }\end{array}$ & $\begin{array}{l}\text { de probabilidade. } \\
\text { orobabilidade. Médias } \\
\text { coluna diferem entre }\end{array}$ \\
\hline
\end{tabular}

$\mathrm{Na}$ tabela 4 nota-se que caules com diâmetros médio e grosso proporcionaram os maiores valores médios de comprimento de parte aérea e índice de velocidade de brotação, diferindo do diâmetro fino. Já para a variável massa de raiz seca, caules finos resultaram em maior massa e o diâmetro médio o menor.

Tabela 4. Resultado das variáveis comprimento de parte aérea (CPA), massa de raiz seca (MRS) e índice de velocidade de brotação (IVB) em função do diâmetro de caules de cana-de-açúcar. $(n=4)$.

\begin{tabular}{cccc}
\hline Diâmetro & CPA $(\mathrm{cm})$ & MRS $(\mathrm{g})$ & IVB \\
\hline Fino & $13,52 \mathrm{~b}$ & $4,74 \mathrm{a}$ & $2,62 \mathrm{~b}$ \\
Médio & $20,55 \mathrm{a}$ & $2,88 \mathrm{~b}$ & $4,16 \mathrm{a}$ \\
Grosso & $21,06 \mathrm{a}$ & $3,37 \mathrm{ab}$ & $4,54 \mathrm{a}$ \\
\hline $\mathrm{CV}(\%)$ & 19,7 & 44,1 & 22,4 \\
\hline $\mathrm{F}$ & $16,09 * *$ & $4,26 *$ & $17,42^{* *}$ \\
\hline **significativo & $\mathrm{a} \quad \mathrm{p}<0,01$ & de probabilidade. \\
*significativo a & $\mathrm{p} \leq 0,05$ de & probabilidade. Médias \\
seguidas de letras diferentes na coluna diferem entre \\
si pelo teste Tukey $\mathrm{p} \leq 0,05$.
\end{tabular}

$\mathrm{Na}$ tabela 5 estão representadas as médias para as variáveis biométricas em função da região caulinar. De maneira geral, a região do ápice proporcionou as maiores médias quando comparadas à região da base para todas as variáveis, com exceção da variável massa de raiz seca, que apresentou comportamento inverso. 
Tabela 5. Resultado das variáveis gemas brotadas (GB), comprimento de parte aérea (CPA), massa de parte aérea seca (MPAS), massa de raiz seca (MRS) e índice de velocidade de brotação (IVB) em função da região caulinar de colmos de cana-de-açúcar. $(n=4)$.

\begin{tabular}{cccccc}
\hline Região & Brotação (\%) & CPA $(\mathrm{cm})$ & MPAS $(\mathrm{g})$ & MRS $(\mathrm{g})$ & IVB \\
\hline Ápice & $96,66 \mathrm{a}$ & $27,09 \mathrm{a}$ & $5,39 \mathrm{a}$ & $2,49 \mathrm{~b}$ & $4,50 \mathrm{a}$ \\
Meio & $89,16 \mathrm{ab}$ & $14 \mathrm{~b}$ & $3,42 \mathrm{~b}$ & $3,75 \mathrm{ab}$ & $3,68 \mathrm{ab}$ \\
Base & $80,83 \mathrm{~b}$ & $14,04 \mathrm{~b}$ & $3,97 \mathrm{~b}$ & $4,74 \mathrm{a}$ & $3,14 \mathrm{~b}$ \\
\hline CV (\%) & 12,7 & 19,7 & 23 & 44,1 & 22,4 \\
\hline $\mathrm{F}$ & $5,89 * *$ & $51,69 * *$ & $12,83^{* *}$ & $5,87^{* *}$ & $7,90^{* *}$ \\
\hline
\end{tabular}

**significativo a $\mathrm{p}<0,01$ de probabilidade. ${ }^{*}$ significativo a $\mathrm{p} \leq 0,05$ de probabilidade. Médias seguidas de letras diferentes na coluna diferem entre si pelo teste Tukey $p \leq 0,05$.

Nota-se que o fator região interferiu na variável comprimento de raiz apenas quando utilizado colmos de diâmetros médio e grosso (Tabela 6). Já o fator região influencia apenas quando utilizada gemas da base do colmo.

Tabela 6. Interação entre diâmetro e região caulinar no comprimento de raiz de gemas brotadas de cana-de-açúcar. $(n=4)$.

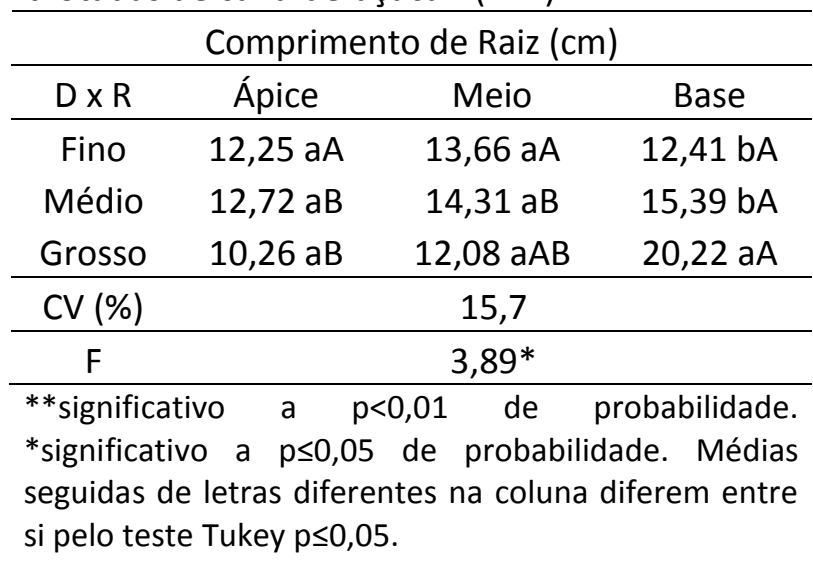

Segundo Fagan et al. (2015), as maiores concentrações de auxina são encontradas nas regiões meristemáticas das plantas e diminui à medida que se distancia do mesmo. No caso da cana-de-açúcar, a produção ocorre no meristema apical vegetativo e é distribuído para o resto da planta por gravidade (BARACAT NETO et al., 2017). No entanto, no presente trabalho, este comportamento do hormônio pode ser observado apenas em colmo de diâmetro grosso, sendo que em colmos de diâmetro fino a região do terço médio e a região basal apresentaram maiores concentrações de auxina e, em colmos de diâmetro médio, o menor teor de auxina foi encontrado na região do terço médio.

Possivelmente, o resultado encontrado para essa variável em plantas com caule de diâmetro fino se deve as condições em que foram encontradas no campo, onde as mesmas estavam tombadas. O tombamento das plantas de canade-açúcar pode ocorrer devido à alta intensidade de chuvas ou ventos fortes, bem quando há elevado desenvolvimento vegetativo, fruto de alta disponibilidade hídrica, manejo nutricional, ou características da própria cultivar (BARBOZA, 2016).

Carlin et al. (2008), estudaram o efeito do tombamento de colmos na produção de cana-deaçúcar, e afirmaram que em caules tombados ocorre uma maior quantidade de auxinas devido ao estímulo para o alongamento dos mesmos, processo que envolve a divisão e o alongamento celular e que o hormônio endógeno auxina está envolvido (TAIZ et al., 2017).

O maior teor de açúcares totais foi encontrado na região da base, corroborando com a afirmação feita por Leite et al. (2009), em tecidos maduros do colmo, onde os processos de crescimento estão praticamente acabados, ocorre uma redução da concentração da enzima invertase ácida solúvel (SAI) e então a invertase neutra (NI) torna-se predominante, a fim de regular o acúmulo ativo de sacarose no vacúolo. $\mathrm{Na}$ fase de maturação, o crescimento vegetativo das plantas de cana-de-açúcar cessa, e então inicia-se o acúmulo dos açúcares produzidos nas folhas em forma de sacarose nos colmos (TOPPA et al., 2010). Esse processo ocorre no sentido da região da basal para o ápice, assim, inicialmente o teor de sacarose aumenta nos entrenós mais velhos, e conforme o progresso da maturação, o teor de sacarose tende a igualar em todas as regiões da planta (AUDE, 1993; CRISTOFOLETTI JUNIOR, 2012).

Já o maior teor de açúcares redutores encontrado para colmos e gemas na região apical, é característico de tecidos jovens e que representam energia prontamente disponível. Segundo Leite et al. (2009), os tecidos imaturos necessitam de hexoses como fonte energia para a 
expansão celular, e a quantidade disponível desses açúcares provavelmente seja regulada pela SAI, que apresenta relação inversa com a quantidade de sacarose e açúcares totais.

O estudo das brotações quando se trabalha com a propagação vegetativa é de grande importância (CARVALHO et al., 2015). O processo de brotação das gemas, assim como os demais processos biológicos, consome energia, e na cana é influenciado pela dominância apical e pela região do colmo, estando diretamente relacionada ao conteúdo de glicose, nitrogênio e água disponível (AUDE, 1993; MANHÃES et al., 2015; BARACAT NETO et al., 2017). A maior porcentagem e velocidade de brotação ocorreu em gemas oriundas da região do ápice da planta que, possivelmente, tenham sofrido influência da dominância apical, ou beneficiadas com a maior disponibilidade de açúcares redutores (glicose) prontamente disponíveis, enquanto as gemas da base, região rica em sacarose, precisaram transformá-la em glicose, e então dar início ao processo. Segundo Manhães et al. (2015), quanto maior a idade do colmo, menor será a disponibilidade de glicose e nutrientes para o desenvolvimento do broto.

Cristofoletti-Junior (2012) e Neto et al. (2017) também observaram maior porcentagem e velocidade de brotação em gemas de cana-deaçúcar da região apical quando comparadas à região basal, bem como Silva et al. (2004), que atribuem este resultado ao fato de que provavelmente as mesmas apresentam-se mais jovens e vigorosas. Devido as características de disponibilidade de reservas e produção de auxinas, ocorre um gradiente decrescente de brotação de gemas da região apical para a região basal, ou seja, de gemas mais novas para as mais velhas (BARACAT NETO et al., 2017). Além disso, por apresentarem maior tempo de formação, as gemas da região basal da planta provavelmente apresentam maior deposição de lignina, uma barreira natural da planta contra a perda de água, desidratação dos tecidos (FREIRE et al., 2014) e ação de fatores bióticos e abióticos (MESCHEDE et al., 2012), podendo inibir ou atrasar a brotação, assim como demandar uma maior quantidade de energia para romper essa barreira.

Colmos de diâmetro grosso que apresentavam mais que $3 \mathrm{~cm}$ promoveram a maior velocidade de brotação. $\mathrm{O}$ diâmetro dos colmos da cana-de-açúcar está relacionado com as características de cada cultivar, perfilhamento, espaçamento e condições ambientais (OLIVEIRA et al., 2014; OLIVEIRA et al., 2016). Colmos de maior diâmetro tem correlação positiva com o acúmulo de reservas, e são formados em período de deficiência hídrica, período que coincide com o acúmulo da sacarose (OLIVEIRA et al., 2016; THOMAS, 2016; MAIA JUNIOR et al., 2018). Em mandioca, Câmara et al. (1998) e Rós et al. (2007) também relataram maior velocidade de brotação a partir de manivas de maior diâmetro. Tofanelli et al. (2003) afirmaram que, na propagação vegetativa de pessegueiro, estacas mais espessas apresentaram maior porcentagem e velocidade brotação, possivelmente pela maior quantidade de reservas disponíveis, favorecendo a emissão dos brotos.

A maior média para comprimento e massa de parte aérea seca das brotações obtidas a partir de gemas de origem da região apical da planta difere dos resultados relatados por Silva et al. (2004) nos quais as maiores médias foram obtidas a partir de gemas localizadas na região do terço médio e região basal de plantas de cana-deaçúcar. Vale ressaltar que, no referido trabalho a avalição ocorreu aos 60 dias após o plantio que, possivelmente, possibilitou a mobilização e uso dos açúcares não redutores. Provavelmente, o maior comprimento de parte aérea de brotos oriundos da região do ápice esteve relacionado a maior velocidade de brotação, que possibilitou maior tempo de crescimento. Além disso, como o crescimento da parte aérea é marcado por intensa divisão, diferenciação e alongamento celular, processos que envolvem a auxina (TAIZ et al., 2017), a maior quantidade de AIA encontrado no ápice pode ter colaborado para o maior desenvolvimento dos brotos oriundos dessa região.

Para a variável comprimento de raiz, a região da base em colmos com diâmetro grosso apresentou as maiores médias, correspondendo também, ao menor teor de auxina, encontrado na mesma região e diâmetro. Segundo Fagan et al. (2015), para que ocorra o desenvolvimento das raízes secundárias, são exigidas concentrações mínimas de auxina e conforme ocorre o aumento dessa concentração, o crescimento é inibido. Também, o maior crescimento de raízes da região basal pode estar relacionado ao maior teor de ATR encontrado nos mini-toletes dessa região. Segundo Carvalho et al. (2015), em estacas provenientes de regiões basais o crescimento das raízes pode ser beneficiado pelo maior acúmulo de reservas. Cristofoletti Junior (2012) não encontrou 
diferença entre os comprimentos de raízes das três regiões em brotações de cana-de-açúcar aos 60 dias após plantio.

O desenvolvimento vegetal ocorre em equilíbrio devido ao controle hormonal, entre auxinas produzidas no ápice da parte aérea e as citocininas produzidas no ápice das raízes, bem como entre os demais grupos hormonais (CAMPOS et al., 2017; TAIZ et al., 2017). Nesse sentido, há a possibilidade de que outros grupos hormonais, que não foram quantificados no presente estudo, também possam interferir na brotação das gemas e desenvolvimento inicial dos brotos, de acordo com a região de origem do caule.

No presente trabalho, em condições de ambiente controlado, a utilização de um minitolete para propagação da cana-de-açúcar mostrou-se viável. A brotação das gemas, assim como o desenvolvimento inicial das mudas de cana-de-açúcar mostraram-se dependentes da quantidade de reservas e auxina (AIA) presentes no colmo e da região caulinar de origem. Porém, Jain et al. (2010), apontam que em condições de campo, mini-toletes com apenas uma gema podem resultar em menor sobrevivência de mudas, devido ao mais rápido esgotamento de reservas.

\section{Conclusões}

O diâmetro do colmo interferiu no teor de auxina sendo o crescimento de raiz relacionado à concentração de auxina endógena.

A brotação das gemas foi influenciada apenas pela região do colmo, sendo a maior brotação obtida a partir da região apical, e maior crescimento de parte aérea em tecidos com maior teor de açúcares redutores disponíveis.

As concentrações de açúcares totais nos colmos e gemas são maiores no ápice e decrescem em direção a base do colmo, sendo os teores diferentes para gemas e caule.

A utilização de mini-toletes para propagação da cana-de-açúcar mostrou-se viável.

\section{Agradecimentos}

À Fundação Araucária do Estado do Paraná pela bolsa de iniciação científica concedida ao primeiro autor e a usina Santa Terezinha, unidade de Umuarama-PR, pelo fornecimento dos colmos de cana-de-açúcar utilizados para propagação vegetativa das plantas no campus.

\section{Referências}

AUDE, M.I.S. Estádio de desenvolvimento da cana-de-açúcar e suas relações com a produtividade. Ciência Rural, v.23, n.2, p.241248, 1993.

BARACAT NETO, J.; SCARPARE, F.V.; ARAUJO, R.B.; SCARPARE FILHO, J.A. Initial development and yield in sugarcane from different propagules. Pesquisa Agropecuária Tropical, v.47, n.3, p.273278, 2017.

BARBOZA, G.C. Fluxo de seiva e relação foliar de cana-de-açúcar (Saccharum officinarum L.). 2016. 138p. Tese (Doutorado em Engenharia Agrícola) - Universidade Estadual de Campinas, Faculdade de Engenharia Agrícola, Campinas, 2016.

BOARETTO, L.F. Análise do transcritôma e proteôma do colmo de cana-de-açúcar relacionada ao metabolismo da sacarose. 2012. 177p. Tese (Doutorado em Fisiologia e Bioquímica de plantas) - Universidade de São Paulo, São Paulo, 2012.

CÂMARA, G.M.S.; GODOY, O.P. Desempenho vegetativo e produtivo de cultivares de mandioca (Manihot esculenta Crantz) a partir de manivas com diferentes diâmetros. Scientia Agricola, v.55, n.2, p.326-331, 1998.

http://dx.doi.org/10.1590/S0103$\underline{90161998000200024}$

CAMPOS, J.A.; OLIVEIRA, N.J.F.; CHAMBA, J.S.V.; COLEN, F.; COSTA, C.A.; FILHO, A.S.S. Brotação de ora-pro-nóbis em substrato alternativo de casca de arroz carbonizada. Holos, v.7, p.148-167, 2017.

http://dx.doi.org/10.15628/holos.2017.6424.

CARLIN, S.D.; SILVA, M.A.; ROSSETTO, F. Parâmetros biométricos e produtividade da canade-açúcar após tombamento dos colmos. Bragantia, v.67, n.4, p.845-853, 2008. http://dx.doi.org/10.1590/s0006$\underline{87052008000400006}$

CARVALHO, J.S.B.; NUNES, M.F.P.N.; CAMPOS, G.P.A.; GOES, M.C.C. Influência de diferentes tipos de estacas e substratos na propagação vegetativa de Hyptis pectinata. Revista de Ciências Agroveterinárias, v.14, n.1, p.89-91, 2015. 
CIVIERO, J.C.; FIORI-TUTIDA, A.C.; DAROS, E.; ALVES, M.J.; FIGUEIREDO, G.G. Crescimento inicial da cana-de-açúcar em função do tamanho do mini-rebolo e aplicação de bioestimulantes. Brazilian Journal of Applied Technology for Agricultural Science, v.9, n.1, p.7-15, 2016. http://dx.doi.org/10.5935/PAeT.V9.N1.01

CONAB. Acompanhamento da safra brasileira de cana-de-açúcar. Brasília, v.6, n.4, 58p, 2019.

CRISTOFOLETTI JUNIOR, S.C. Fisiologia da emergência e perfilhamento em mini-toletes de variedades de cana-de-açúcar. 2012. $92 \mathrm{f}$. Dissertação (Mestrado em Ciências) - ESALQ, Piracicaba, 2012.

DUBOIS, M.; GILLES, K.A.; HAMILTON, J. K.; REBERS, P.A.; SMITH, F. Colorimetric method for determination of sugars and related substances. Analytical Chemistry, v.28, n.3, p.350-356, 1956.

FAGAN, E.B.; ONO, E.O.; RODRIGUES, J.D.; CHALFUN JÚNIOR, A.; DOURADO NETO, D. Fisiologia vegetal: reguladores vegetais. São Paulo: Andrei, 2015. 300p.

FREIRE, C.S.; SIMÕES, A.N.; VIEIRA, M.R.S.; BARROS JÚNIOR, A.P.; COSTA, F.B. Qualidade de raízes de mandioca de mesa minimamente processada nos formatos minitolete e rubiene. Revista Caatinga, v.27, n.4, p.95-102, 2014.

GORDON, S.A.; WEBER, R.P. Colorimetric estimation of indole acetic acid. Plant Physiology, v.26, n.1, p.192-195, 1951.

JAIN, R.; SOLOMON, S.; SHRIVASTAVA A.K.; CHANDRA, A. Sugarcane bud chips: A promising seed material. Sugar Tech, v.12, n.1, p.67-69, 2010. https://doi.org/10.1007/s12355-010-0013$\underline{9}$

LANDELL, M.G.A.; CAMPANA, M.P.; FIGUEIREDO, $P$. Sistema de multiplicação de cana-de-açúcar com uso de mudas pré-brotadas (MPB), oriundas de gemas individualizadas. Campinas: Instituto Agronômico, 2012. 16p.

LEITE, G.H.P.; CRUSCIOL, C.A.C.; LIMA, G.P.P.; SILVA, M.A. Reguladores vegetais e atividade de invertases em cana-de-açúcar em meio de safra. Ciência Rural, v.39, n.3, p.718-725, 2009.
http://dx.doi.org/10.1590/S0103$\underline{84782009000300014}$

MAGUIRE, J.D. Speed of germination-aid in selection and evaluation for seedling emergence and vigor. Crop Science, v.2, n.1, p.176-177, 1962.

MAIA JÚNIOR, S.O.; SILVA, J.A.C.; SANTOS, K.P.O.; ANDRADE, J.A.; SILVA, J.V.; ENDRES, L. Caracterização morfológica e produtiva e suas correlações em cultivares de cana-de-açúcar. Ciência Agrícola, v.16, n.1, p.31-42, 2018.

MANHÃES, C.M.C.; GARCIA, R.F.; FRANCELINO, F.M.A.; FRANCELINO, H.O.; COELHO, F.C. Fatores que afetam a brotação e o perfilhamento da cana-de-açúcar. Vértices, v.17, n.1, p.163-181, $2015 . \quad$ http://dx.doi.org/10.5935/18092667.20150011

MESCHEDE, D.K.; VELINI, E.D.; CARBONARI, C.A.; MORAES, C.P. Teores de lignina e celulose em plantas de cana-de-açúcar em função da aplicação de maturadores. Planta Daninha, v.30, n.1, p.121-127, 2012. http://dx.doi.org/10.1590/S0100$\underline{83582012000100014}$

MILLER, G.L. Use of dinitrosalicylic acid reagent for determination of reducing sugar. Analytical Chemistry, v.31, p.426-428, 1959.

NAMJOO, M.; RAZAVI, J.; KHANI, A. Fabrication and evaluation of a metering device for a sugarcane billet planter. Yyü Tar Bil Derg, v.25, n.1, p.1-12, 2015.

NETO, J.B.; SCARPARE, F.V.; ARAÚJO, R.B.; SCARPARE-FILHO, J.A. Desenvolvimento inicial e produtividade em cana-de-açúcar a partir de diferentes propágulos. Pesquisa Agropecuária Tropical, v.47, n.3, p.273-278, 2017.

OLIVEIRA, A.R.; BRAGA, M.B.; SANTOS, B.L.S.; WALKER, A.M. Biometria de cultivares de canade-açúcar sob diferentes reposições hídricas no vale do submédio São Francisco. Revista Energia na Agricultura, v.31, n.1, p.48-58, 2016. http://dx.doi.org/10.17224/EnergAgric.2016v31n 1p48-58

OLIVEIRA, F.M.; AGUILAR, P.B.; TEIXEIRA, M.F.F.; ASPIAZÚ, I.; MONÇÃO, F.P.; ANTUNES, A.P.S. 
Características agrotecnólogicas de cana-deaçúcar em diferentes épocas de supressão de irrigação e níveis de adubação. Semina: Ciências Agrárias, v.35, n.3, p.1587-1606, 2014. http://dx.doi.org/10.5433/1679-

0359.2014v35n3p1587.

RÓS, A.; SILVA, A.C.; NARITA, N. Emergência e desenvolvimento inicial de plantas de mandioca (Manihot esculenta Crantz) obtidas de manivas com diferentes diâmetros. Revista Raízes e Amidos Tropicais, v.3, n.1, p.289-292, 2007.

SILVA, J.P.N.; SILVA M.R.N. Noções da cultura da cana-de-açúcar. Inhumas: IFG, 2012. 105p.

SILVA, M.A.; CARLIN, S.D.; PERECIN, D. Fatores que afetam a brotação inicial de cana-de-açúcar. Revista Ceres, v.51, n.296, p.457-466, 2004.

SOBRINHO, O.P.L.; SILVA, G.S.; PEREIRA, A.I.S.; SOUSA, A.B.; CASTRO JÚNIOR, W.L.; SANTOS, L.N.S. A cultura da cana-de-açúcar (Saccharum officinarum) e o manejo da irrigação. Revista em Agronegócio e Meio Ambiente, v.12, n.4, p.16051625, 2019. http://dx.doi.org/10.17765/2176$\underline{9168.2019 v 12 \mathrm{n} 4 \mathrm{p} 1605-1625}$

THOMAS, A.L. Desenvolvimento das plantas de batata, mandioca, fumo e cana-de-açúcar. Porto Alegre: UFRGS, 2016. 76p.

TOFANELLI, M.B.D.; RODRIGUES, J.D.; ONO, E.O. Enraizamento de estacas lenhosas de pessegueiro cv. Okinawa em diferentes diâmetros de ramos, substratos e recipientes. Ciência Rural, v.33, n.3, p.437-442, 2003. http://dx.doi.org/10.1590/S010384782003000300007

TAIZ, L.; ZEIGER, E.; MØLLER, I.M.; MURPHY, A. (Org). Fisiologia e desenvolvimento vegetal. 6 ed. Porto Alegre: Artmed, 2017. 888p.

TOPPA, E.V.B.; JADOSKI, C.J.; JULIANETTI, A.; HULSHOF, T.; ONO, E.O.; RODRIGUES, J.D. Aspectos da fisiologia de produção da cana-deaçúcar (Saccharum Officinarum L.). Pesquisa Aplicada \& Agrotecnologia, v.3, n.3, 2010. 